\title{
doispontos:
}

\section{Freud, Binswanger e a concepção de homo natura}

\author{
Ana Carolina Soliva Soria \\ Universidade Federal de São Carlos
}

\begin{abstract}
Resumo: Em A concepção freudiana de homem à luz da antropologia, além de ressaltar as características originais do pensamento de Sigmund Freud, Ludwig Binswanger examina as ideias do psicanalista austríaco, a partir da concepção de homo natura, que reduziria as categorias fundamentais da existência humana a fatores biológicos. É no que denomina uma antropologia fenomenológica que encontra a saída para o reducionismo no qual a psicanálise se achava encerrada e a partir dela pretende devolver a esta disciplina sua dimensão prática. O presente artigo visa reconstruir os argumentos do psicanalista suíço e apresentar uma resposta às suas ideias.
\end{abstract}

Palavras-chave: Freud; Binswanger; homo natura; pulsão; mecanismo; psicanálise.

Abstract: In the text "Freud's conception of man in light of anthropology", more than highlight the original characteristics of Sigmund Freud's thoughts, Ludwig Binswanger examines the ideas of the Austrian psychoanalyst from the conception of homo natura, which would reduce the fundamental categories of human existence to biological factors. It is through what it is called phenomenological anthropology that Binswanger finds a way out to the inference in which Freud's psychoanalysis was in and from anthropology intends to return to psychoanalysis its practical dimensions. The present article focus on reconstructing the arguments of the Swiss author and presents an answer to his ideas.

Keywords: Freud; Binswanger; homo natura; drive; mechanism; psychoanalysis.

De formação psicanalítica, Ludwig Binswanger pode ter sua relação com a doutrina freudiana resumida por uma frase que lhe foi dita por Sigmund Freud em 1913, em uma de suas visitas ao psicanalista em Viena: "Ide comigo o mais longe que podeis; e de resto, continuaremos bons amigos". Como uma espécie de presságio, esta frase nos permite antever o caminho trilhado por Binswanger: para ele, Freud foi um consciencioso explorador da natureza, cujas ideias mantiveram-se dentro dos limites da justa exigência crítica científica; contudo, sua obra testemunharia fracas necessidades filosóficas, que subtrairiam de seu pensamento problemas fundamentais como o da liberdade e o da autonomia. Se Freud é original em muitos pontos, sua doutrina revelar-se-ia, para Binswanger, restritiva em muitos outros. É na tentativa de ultrapassar as limitações da psicanálise freudiana que o suíço acaba por recorrer à filosofia, sobretudo de inspiração heideggeriana, para propor uma antropologia filosófica fundamentada na analítica existencial.

Um dos pontos principais da crítica de Binswanger à psicanálise freudiana se refere à concepção de homem aí presente. Para melhor compreendermos a direção tomada pelo autor suíço em suas críticas ao psicanalista vienense, nossa exposição se centrará em uma conferência de Binswanger proferida por ocasião do $80^{\circ}$ aniversário de Freud, intitulada "A concepção freudiana de homem à luz da antropologia" (1936). Nossa intenção não é a de esgotar a análise da relação entre os dois autores, tanto no que diz respeito ao conjunto de problemas levantados dessa relação quanto ao conjunto de autores que se dedicaram a ela. O presente texto se concentra no exame da concepção do que Binswanger denomina homo natura em Freud, e numa possível resposta às críticas que aquele dirige a este. Mais precisamente, nosso artigo se 
centra na análise de dois argumentos expostos pelo autor suíço: o de que há uma fraca fundamentação filosófica na concepção freudiana de homem e de que sua unilateralidade acaba por mecanizar a totalidade da experiência humana. Reconstituiremos os argumentos do autor suíço a partir dos seguintes aspectos: a determinação do lugar da concepção freudiana de homem frente ao pensamento filosófico de seu tempo; a apresentação da ideia de homo natura freudiana como não sendo nem filosófica e tampouco psicológica, mas biológica e, nesse sentido, incapaz de dar conta de categorias fundamentais da existência, tais como a religião, a moral e as artes; e o caminho sugerido por Binswanger para o reducionismo biológico freudiano, a saber: a antropologia fenomenológica. Na sequência, tomaremos três textos de Freud, a saber: $A$ concepção das afasias, A interpretação dos sonhos e Além do princípio do prazer, para apresentar uma possível resposta ao argumento segundo o qual o autor austríaco reduziria o homem a processos mecânicos de natureza biológica, bem como para mostrar que suas ideias se inserem num importante debate filosófico sobre a impossibilidade de se explicar em termos mecânicos a vida psíquica humana.

\section{A CRÍTICA DE BINSWANGER A FREUD}

O exame da concepção freudiana de homem empreendido pelo psicanalista suíço é acompanhado da determinação do lugar de Freud na história do pensamento. Binswanger situa a psicanálise perante duas disciplinas: a filosofia e a psicologia médica (não trataremos desta última no presente texto). $\mathrm{O}$ próprio termo utilizado para caracterizar o homem freudiano não é retirado da obra de Freud, e sim de Nietzsche, como admite o autor em outro texto escrito em 1956, intitulado "Recordações de Sigmund Freud", em que relata alguns pontos de sua amizade com o psicanalista austríaco.

Vejamos, como um primeiro ponto de contato de Freud com o seu tempo, o termo homo natura tal como aparece em Nietzsche. Dentre os usos feitos pelo filósofo, a expressão em questão pode ser encontrada em "Para além de bem e mal", $\$ 230$. Citamos o trecho:

[...] reconverter o homem para a natureza; triunfar sobre as muitas interpretações e segundos sentidos vaidosos e delirantes que até agora foram rabiscados e pintados sobre aquele eterno texto fundamental homo natura; fazer com que o homem, doravante, fique diante do homem como já hoje, endurecido na disciplina da ciência, ele fica diante de outra natureza, com intrépidos olhos de Édipo e tapados ouvidos de Odisseu, surdo aos engodos dos velhos passarinhos metafísicos, que por demasiado tempo lhe flautaram ao ouvido: "Tu és mais! Tu és superior! Tu és de outra ascendência!" - pode ser uma tarefa estranha e maluca, mas é uma tarefa - quem haveria de negá-lo! (NIETZSCHE, 1974, p. 296-97)

No trecho citado, é possível notar que Nietzsche aceita uma continuidade entre homem e natureza. O propósito nietzschiano de repensar o homem como corpo ou organismo já nos mostra a possibilidade dessa continuidade. Para ele, o homem deve ser reconvertido para a natureza, sentido oposto daquele tomado pelos "velhos passarinhos metafísicos" que visavam elevar o homem a um estatuto superior ao da natureza, como um algo a mais, com outra origem que não a natural. Do reconhecimento do fato de que o homem se pôs além ou acima da natureza, Nietzsche fala de uma nova tarefa - "estranha e maluca" -, qual seja: a de retirar as camadas de pinturas e enfeites que dissimulam com mentiras, com palavras morais, $\mathrm{o}$ texto fundamental homo natura.

Ora, e por que tomar uma expressão de Nietzsche para exprimir a concepção freudiana de homem? Binswanger não estaria com isso partindo de um ponto externo, estranho à psicanálise, para indicar de modo artificial os seus limites? O contraponto com Nietzsche permite ao leitor compreender em que sentido Binswanger aproxima Freud do pensamento filosófico de sua época e em que sentido ele se distancia. 
Em seu texto "A concepção freudiana de homem à luz da antropologia", o autor suíço afirma que o fundamento do homo natura de Nietzsche se encontra sobre o mesmo plano que o de Freud, a saber: o de que "em toda parte é concedido à corporeidade uma competência de juiz na determinação do que o homem é no fundo de seu ser" (BINSWANGER, 1970, p. 212). O autor austríaco reconverteria o homem à natureza e encontraria na corporeidade o ponto de apoio para isso: o corpo seria uma espécie de "texto fundamental" sobre o qual se assentariam enfeites estranhos a ele e que pretenderiam elevar o homem acima de sua condição. Para Binswanger, o "bem", a "moral" da doutrina freudiana, ao contrário da tradição, não existem por si mesmos, mas apenas pela coerção imposta pela cultura às necessidades corporais. A positividade dos valores estaria assentada sobre uma coerção imposta aos impulsos do corpo. A proposta de uma volta a um texto primeiro pode ser entendida como a consideração da corporeidade, de suas carências e necessidades, de sua dor, como tendo um papel positivo no conhecimento do homem, já que seria na dor que se descobriria a condição intrínseca e verdadeira da humanidade. A moral, o bem não seriam para Freud potências ativas, libertadoras e criadoras, mas, antes, frutos da transformação de impulsos narcisistas. Pelo corpo, descobrir-se-ia que o homem vive psicologicamente acima de sua situação fundamental real. Segundo Binswanger, através da reconversão do homem à natureza, Freud, assim como Nietzsche, apontaria para a "quinta-essência da hipocrisia privada e cultural" (1970, p. 203). Para ele, apenas o doloroso pode ser verdadeiro; todo o resto é superestrutura, sublimação, ilusão.

Ora, se Binswanger aproxima os pensamentos de Freud e Nietzsche a ponto de utilizar um termo retirado do texto do segundo para caracterizar a noção de homem do primeiro, não estaria ele equivocado quando afirma que há em Freud fracas necessidades filosóficas? Aqui se desenham as especificações de Freud, a saber: sua concepção de pulsão. Binswanger escreve que se em Nietzsche há um acento sobre a modificação intrínseca que, tal como em Goethe, devemos "renunciar à nossa existência para existir" (1970, p. 224), em Freud, as coerções que transformam o homem de "mau" em "bom", de egoísta em sociável, seriam impostas originalmente de fora para dentro, para só posteriormente se tornarem internas. Na psicanálise freudiana, toda modificação da existência teria como fundamento último algo externo ao próprio ser transformado. A crítica de Binswanger não se dirige apenas ao fato de Freud ter dado à corporeidade um lugar privilegiado, mas, antes, porque as forças que brotam do corpo, a saber: as pulsões, seriam o resultado de constrangimentos externos que posteriormente foram incorporados ao homem. Ora, ao fazer isso, o psicanalista daria à categoria fundamental do homem um caráter condicionado, fazendo com que ela perca seu fundo livre e autônomo. O acento principal do pensamento freudiano já não recairia mais sobre o poder ativo da modificação, mas sobre o que na modificação permanece sempre igual a si mesmo. Ao contrário do que encontramos em Goethe e Nietzsche, afirma o autor suíço, não haveria em Freud uma "meta-morfose" (1970, p. 224), ou seja, o desaparecimento da forma original enquanto tal para o aparecimento de seus desdobramentos. Ao dar à forma original, unitária da modificação (isto é, às pulsões), a qualidade de uma coerção primeiramente adquirida para só em seguida se tornar hereditária, Freud não resolveria, mas saltaria por cima de um problema de importância capital: o de um fundamento prático do homem. Desse modo, ao invés de tomar como caminho uma profunda reflexão sobre as diferentes possibilidades de existência humana e de sua expressão na religião, na cultura e mesmo na filosofia, a psicanálise freudiana desviar-se-ia do problema da prática para descrever o homem como um fato biológico, determinado por leis necessárias e invariáveis. O homem freudiano não seria, tal como afirma Binswanger, um homem real que age e pensa de modo livre e autônomo, mas apenas uma ideia duramente construída pela penetração discursiva na técnica da natureza - é uma criação exigida pela investigação naturalista.

Se Freud se aproximaria de Nietzsche ao reconverter o homem à natureza, as semelhanças cessariam, segundo Binswanger, sobretudo no que toca à concepção freudiana de necessidade corporal. Para o psicanalista suíço, a originalidade de Freud, o que distinguiria suas ideias de homo natura das de outros autores 
e lhe conferiria sua marca própria, encontrar-se-ia naquilo que denomina "pulsão". Tal como afirma o autor, é no jogo pulsional entre potências opostas que a corporeidade se situaria em Freud. Esse lugar não seria iluminado pela clareza própria da consciência (secundária e derivada), mas relegado à obscuridade, ao desconhecido, ao inconsciente. O homem freudiano seria, no fundo de seu ser, corporeidade, isto é, na expressão de Binswanger $(1970,214)$ : brinquedo, joguete passivo de potências invisíveis e não controladas pela consciência (pelo eu).

Para o psicanalista suíço, ao se colocar como explorador da natureza e explicar a multiplicidade do que denomina "ser-homem" a partir de um princípio único, reconstruído de modo artificial e abstrato, a doutrina freudiana seria levada a cabo por um método semelhante ao de qualquer outra ciência natural (a química ou a física, por exemplo). A psicanálise reduziria as diferenças qualitativas a quantitativas na combinação entre elementos. Desse modo, escreve o autor suíço, quanto maior é a necessidade corporal, menos se pode determinar as diferenças entre os indivíduos. Se a corporeidade está situada no jogo pulsional, as pulsões não são elementos de individualização; ao contrário, elas nivelam e uniformizam a essência multiforme do homem.

A vida individual não se diferenciaria, em seu fundo, da vida em geral. Para o autor suíço, a psicanálise freudiana nos levaria a uma concepção de vida individual como produto do embate de forças, da luta entre a Vida e a Morte; embate caótico, obscuro e inabordável que só poderia ser descrito em comparação com o Eu organizado, como o seu negativo e, portanto, como algo jamais alcançado com precisão. Ao contrário do eu consciente, as pulsões não se organizam segundo uma vontade única e individualizada. Elas seriam regidas por um afã narcisista, que quer realizar suas necessidades sem levar em consideração outros impulsos.

E como determinar diante dessa dispersão pulsional a fronteira entre o corpóreo e o psíquico? Em Pulsões e destinos da pulsão (1999 [1915a], p. 214), Freud afirma que a pulsão é o conceito limiar entre esses dois diferentes campos. Ela tem sua fonte no corpo, conforme sua necessidade aumenta quantitativamente, com mais força ela se representa no psiquismo. Sua aparição no psiquismo é feita apenas mediante um representante psíquico, nunca diretamente. Apoiado sobre essa ideia, Binswanger afirma que a corporeidade se situaria, na obra freudiana, no jogo pulsional, e se este não tem uma autonomia em sua apresentação psíquica, a própria concepção de corpo, suas potências orgânicas, seriam relegadas a uma construção intelectual. Com isso, afirma o autor suíço, não se chega de modo algum ao próprio corpo, ao organismo, mas só ao que dele se representa psiquicamente. Como bem nos lembra Binswanger, no capítulo teórico de $A$ interpretação dos sonhos, o aparelho psíquico é descrito como um preparado anatômico. Nele encontramos "órgãos" de percepção e motilidade que têm relação com o eu consciente, e que se opõem ao reservatório pulsional inconsciente. Contudo, afirma ele, se o aparelho psíquico é edificado sobre o "corpo", essa corporeidade é confeccionada como um desenho em um pedaço de papel. $\mathrm{Na}$ leitura de Binswanger, ao tentar apreender o funcionamento psíquico segundo o modelo fisiológico, Freud reduziria o psiquismo a uma reprodução esquemática, ainda que virtual, de órgãos corporais, ou, ainda, de funções vitais - o homo natura do autor austríaco seria assim um homo vita. Ele parece, assim, cair em uma armadilha: quanto mais tenta se aproximar do corpóreo, mais é levado para longe deste por suas construções teóricas. Ao expressar o funcionamento psíquico aos moldes de um como se fosse assim (de um als $o b$ ), Freud começaria a exposição desse funcionamento pela própria criação, mesmo que virtual, dos "órgãos" que o constituiriam. Essa construção nada teria de orgânica, pois colocaria leis físicas e químicas em seu fundamento. O psicanalista austríaco reduziria, segundo o autor suíço, toda a multiplicidade da existência humana ao simples funcionamento de uma máquina, cujas regras de existência seriam abstratas e necessárias. Para Binswanger, a multiplicidade da essência humana se reduziria a combinações matemáticas de elementos quantificáveis. 
Em outro texto, intitulado "Freud e a concepção da psiquiatria" (1970), Binswanger afirma que ao dar às potências vitais a qualidade de categorias fundamentais do ser-homem, Freud retirar-se-ia do campo da psicologia: seu conceito de aparelho psíquico, regido pelo princípio de prazer, e ainda a tópica, a dinâmica e a economia desse aparelho não poderiam ser definidos como concepções psicológicas. O pensamento de Freud, assim como a psicologia médica de seu tempo, teria de ser compreendido muito mais como uma biologia do que como uma ciência psicológica. Isso é confirmado, segundo o autor suíço, pelas afirmações de Freud de que os defeitos de sua descrição desapareceriam se no lugar de termos psicológicos pudesse utilizar os fisiológicos e químicos (1970, p. 177ss).

É por esse motivo que Binswanger descreve o homo natura como a construção árdua de um cientista natural: a máquina complicada de Freud, que teria nas potências cegas o seu motor, acabaria, para ele, por destruir qualquer possibilidade de liberdade e autonomia humanas. As pulsões não seriam potências criadoras e libertadoras, mas, antes, potências destrutivas da experiência total do ser-homem. Ao reconverter o homem para o seio da natureza, o homo natura freudiano seria expulso da dimensão moral: tudo funcionaria mecanicamente, a necessidade ocuparia todos os lugares sem deixar espaço para a liberdade; o mecanismo ocuparia o lugar da decisão e da reflexão. A empreitada prática seria, com isso, reduzida à tarefa teórica; a moral, às leis necessárias; a historicidade, à mera repetição. $\mathrm{O}$ que quer dizer que Freud teria, assim, naturalizado o homem e a cultura, subtraindo deles sua dimensão histórica.

Ao identificar o ser-homem com o corpo, colocado sob o aspecto caótico e inconsciente, para Binswanger, a psicanálise de Freud julgaria o homem de modo unilateral e ontologicamente falseado. A construção maquinal do psicanalista austríaco, quando colocada como fundamento do homem, contaminaria a prática, a saber: o curar. O modelo da unilateralidade e univocidade das pulsões seria sentido também na relação médico-paciente, tornada, segundo o autor suíço, apessoal ou impessoal, desconsiderando a relação-entre-nós (1970, p. 226). Tal como nas ciências naturais, a relação médico-paciente estaria contaminada pela irreversibilidade e pela fixidez das relações sujeito-objeto. $O$ paciente seria tomado como objeto construído pelo investigador para responder às suas exigências teóricas. Seu discurso, fundamentado sobre potências corporais cegas, estaria destituído de significação.

Ao propor uma antropologia de inspiração fenomenológica como a saída para os impasses do pensamento freudiano, Binswanger pretende recuperar não apenas a dimensão prática da psicanálise, mas também reencontrar a significação das construções humanas e da comunicação médico-paciente. Dito de outro modo, ao recolocar a questão antropológica no interior da psicanálise, Binswanger se refere ao homem, não como objeto de um saber naturalista, visto a partir de sua exterioridade, mas a partir de sua subjetividade. Essa nova direção não seria possível sem descentralizar a relação sujeito-objeto (que opõe subjetividade e objetividade - oposição própria da investigação da natureza) e fazer com que o outro deixe de estar fundado nas exigências de conhecimento do cientista. Binswanger funda, assim, a objetividade sobre a subjetividade das relações inter-humanas.

A intersubjetividade a que se refere o autor suíço poderia ser encontrada justamente no que a psicanálise freudiana deixaria escapar. Para ele, basta abrirmos qualquer página dos textos de Freud que veremos que se trata de algo não declarado pelo autor, a saber: de "nossa" alma pela qual "nós" nos afirmamos na vida; trata-se de "nossa" vida da alma, de "nossos" pensamentos. O que os pronomes antes enumerados permitem vislumbrar é exatamente o que a psicanálise de Freud põe entre parênteses, isto é, que se trata do que o suíço denomina o "ser-presente como nosso" (o ser-presente como meu, teu, seu etc.) e de uma comunicação existencial, de uma relação-entre-nós (melhor dito, da relação de uma pessoa com outra, da comunicação entre semelhantes). Ao colocar as relações pessoais entre parênteses, a psicanálise freudiana perderia de vista o foco da pessoa que fala e retiraria o sujeito das relações inter-humanas. Ela isola e fixa a ipseidade (o si, o Selbst) na forma artificial de um Eu ou Sobre-eu (Ich, Überich), expulsando-a do 
domínio da existência. Desse modo, quando Freud se refere ao "nós" ou ao "nosso", já não se trataria mais de "nós-mesmos", isto é, do que o homem tem de real e concreto, mas de uma imagem fixa e artificial, de um construto teórico.

Binswanger não quer com isso desqualificar as descobertas de Freud, e sim mostrar que o procedimento analítico-psicológico, que tomaria como o fundamento do homem o fato biológico, revelaria apenas um modo determinado de se situar em relação às coisas do mundo. Para além desse fundamento, Binswanger quer buscar outro que permita a compreensão do homem em sua existência total. Com isso, o autor suíço pretende apontar um caminho trilhado a partir de dentro, "em-nós-mesmos" (1970, p. 227). Tal como defende, seria apenas da real compreensão-de-si da humanidade, das possibilidades mais próprias do seu ser, que poderia surgir uma antropologia. Seria apenas no exercício antropológico que se poderia encontrar o fundamento da psicologia (e não na biologia).

Binswanger fala de um homem fundado sobre si mesmo, como condição de sua própria existência. Se a psicanálise freudiana visava, segundo o autor suiço, a uma reconversão do homem para a natureza, podemos dizer que este último pretendia recuperar o fundamento prático da condição humana. A tarefa de devolver ao homem a sua condição moral é, para ele, inseparável de sua determinação espacial, temporal e histórica. Na ciência natural, a historicidade humana seria conhecida apenas como história natural; em sua antropologia fenomenológica, o que teríamos é um ser que olha nos olhos de seu destino e do destino da humanidade, que decide seu caminho, numa só palavra: autônomo. Com isso, o autor suíço tem a intenção de pôr no fundamento da psicologia um ipse que se assenta sobre si mesmo e chega a uma penetração mais própria das possibilidades do ser enquanto moral e autônomo, enquanto historicamente determinado, e não a partir do que faz do homem um animal.

No final de O sonho e a existência, Binswanger (1954, p. 193) afirma que a vida, enquanto função biológica, é outra vida que a enquanto história, e que ambas têm o mesmo fundamento: a existência. Em sua introdução à tradução francesa desta obra, Michel Foucault afirma que Binswanger vai além de Freud, já que não vê o sonho apenas como a realização de um desejo ou como algo a ser decifrado no processo terapêutico de cura das patologias psíquicas. Foucault afirma que a originalidade de Binswanger é mostrar que o sonho é o protótipo do modo mesmo de existência do Dasein (da présence à l'être, da existence) (BINSWANGER, 1954, p. 10). Desse ponto de vista, o sonho, com seus elementos constituintes, não indicaria uma imagem arcaica, uma fantasia (tal como em Freud); ao contrário, "sonhar", escreve Foucault, "é para o sujeito que sonha a maneira radical de fazer a experiência de seu mundo", um mundo inteiramente pertencente a quem sonha e que revela o modo próprio de sua existência. $\mathrm{O}$ sonho é a abertura para uma história; é um momento de exercício de liberdade para nos darmos um mundo próprio e significativo. A imaginação que move o sonho é também a que move a existência. Em outro texto, Binswanger afirma: "O sujeito do sonho não é tanto o personagem que diz 'Eu', mas, na realidade, é o sonho inteiramente, com o conjunto de seu conteúdo onírico" (BINSWANGER, 1970, p. 85-86).

Ao rever a psicanálise à luz de uma fenomenologia existencial, Binswanger acreditou retirar o homem freudiano do movimento circular e repetitivo (de uma espécie de eterno retorno do idêntico, para usarmos a comparação do autor), movimento próprio da história natural, para situá-lo no fluxo do movimento histórico intrínseco ao homem. A tentativa de recolocar as questões morais no cerne da psicologia foi feita, contudo, sob os protestos de Freud. Em uma carta enviada a Binswanger em 8 de outubro de 1936, após tomar conhecimento do conteúdo da conferência do amigo em homenagem aos seus 80 anos, Freud se definiu como um pensador revolucionário, ao contrário do suíço que, segundo ele, seria um conservador. Aos olhos do austríaco, ao recuperar a religião, a moral e as artes, ou seja, os andaimes superiores das edificações humanas, e fazer deles categorias fundamentais da existência, o amigo não estaria propondo outra coisa senão retroceder o posicionamento inovador da psicanálise. E esse posicionamento estaria em 
não inverter a ordem dos andares do edifício. Dito de outro modo, em não fazer da cobertura o sustentáculo da construção. Nas palavras de Freud: "Eu jamais habitei senão o nível do solo, e o porão do edifício".

Segundo Monzani, "uma leitura de Freud orientada pela fenomenologia existencial" direcionou "direta ou indiretamente" uma "grande corrente" de interpretação dos textos do psicanalista austríaco. "A denúncia de mecanicismo", contudo, "não fornecia uma visão completa das características principais do discurso psicanalítico" (1989, p. 68). Não é nossa intenção reproduzir o argumento de Monzani, que, para encontrar aquilo que "destoava" do discurso freudiano na explicação fenomenológica existencial, retoma argumentos de autores como J. Hyppolite e P. Ricoeur, para, por fim, se posicionar de maneira original diante desses autores e mostrar as características revolucionárias do discurso freudiano. Nossa intenção aqui é muito mais modesta: tentaremos delinear a posição de Freud a partir de dois pontos que figuram na crítica de Binswanger, já apontados anteriormente. São eles: a análise da mecanização do homem e de suas relações, e as fracas necessidades filosóficas presentes na obra de Freud. Nossa intenção não é a de rebater ponto a ponto os argumentos do autor suíço, mas mostrar que as ideias de Freud podem estar fundadas sob um solo ou sustentáculo distinto daquele entendido por Binswanger. Vejamos abaixo.

\section{UMA POSSÍVEL RESPOSTA ÀS CRÍTICAS DE BINSWANGER}

Alguns anos antes da publicação de $A$ interpretação dos sonhos (1900), obra tida pelos comentadores como inaugural da psicanálise, Freud redige Sobre a concepção das afasias: um estudo crítico (1891). Gostaríamos de trazer para nossa discussão o início desse texto, em que Freud revê a teoria localizacionista de Wernicke, sem, contudo, entrarmos no mérito do texto como um todo. Entendemos que a crítica exposta nas primeiras páginas às ideias de Wernicke nos oferece um ponto exemplar para a intelecção do que vem a ser uma explicação mecânica dos processos corporais e psíquicos para, na sequência da argumentação, apresentarmos como o autor austríaco recusa tal posição.

Segundo Freud, com a teoria de Broca foi possível atribuir à parte frontal esquerda do cérebro, mais especificamente, à sua terceira circunvolução frontal, ${ }^{2}$ a articulação motora da linguagem, uma vez que os resultados de autópsias lhe permitiram concluir que uma lesão nessa parte do cérebro acarretaria a perda total ou uma diminuição significativa da linguagem articulada, sem perda da inteligência ou das demais funções da linguagem. Wernicke, por outro lado, descreve a contrapartida da afasia de Broca, a saber: a perda da compreensão da linguagem com a preservação da capacidade de se servir de sua articulação motora. A afasia descrita por ele teria sua origem em uma lesão encontrada na primeira circunvolução temporal esquerda. A partir das descrições de Broca e Wernicke, temos, respectivamente, a afasia motora e a sensória.

Os dados apresentados por Broca e Wernicke acenderam, segundo Freud, a esperança de poder explicar "cada uma das várias manifestações da dissociação da capacidade de linguagem, tal como demonstrada por exames clínicos, por meio de lesões específicas correspondentes no órgão central” (FREUD, 2013, p. 19). Wernicke teria dado o primeiro passo: tendo os distúrbios da linguagem uma localização precisa no cérebro (nos centros antes mencionados ou na ligação entre eles), seria possível determinar o processo fisiológico da linguagem segundo o modelo do arco reflexo, ou ainda, como um "reflexo cerebral", disposto a partir de dois pontos antagônicos: o sensório e o motor. Os sons da língua chegariam ao lobo temporal esquerdo, centro sensório da linguagem, e dali seriam enviados ao lobo frontal, centro motor, que conduziria os impulsos para a articulação da fala.

Semelhante funcionamento fisiológico da linguagem, simples em sua compreensão, não se limita à exposição genérica das localizações anatômicas. Ele chega ao ponto mais elementar da construção do cére- 
bro, em que se poderia indicar pontualmente na máquina cerebral a origem de certa patologia da linguagem, a saber: nas células. Reproduzimos aqui uma citação de Wernicke apresentada por Freud no texto:

\footnotetext{
O córtex cerebral com seus 600 milhões de corpos corticais, segundo a avaliação de Meynert, proporciona uma quantidade bastante grande de locais de armazenamento, nos quais as incontáveis impressões sensórias advindas do mundo externo podem ser armazenadas, uma após a outra, de forma imperturbada. É com tais resíduos de estímulos transcorridos, que denominaremos de imagens da lembrança, que está povoado o córtex cerebral (WERNICKE apud FREUD, 2013, p. 20).
}

Teríamos, segundo o modelo de Wernicke, o centro sensório da linguagem povoado por inúmeras células capazes de armazenar as imagens dos sons - a chamada recordação sensorial das palavras -, e a destruição das células que compõem esse centro ocasionaria a "incapacidade de entendimento da linguagem - a afasia sensória, surdez verbal” (2013, p. 20). O mesmo se daria com o centro motor da linguagem: a destruição das células que o compõem acarretaria a perda da imagem do movimento da linguagem, que teria como consequência a perda da inervação dos "núcleos nervosos motores do cérebro para a produção dos sons da linguagem - afasia motora" (2013, p. 20). E uma vez que os dois centros estão ligados por uma região física no cérebro, "exclusivamente através de fibras de substância branca ou também através da mediação da substância cinzenta da ínsula” (2013, p. 21), a destruição das células dessa região acarretaria confusão e insegurança na compreensão e articulação das palavras, apesar destas duas funções permanecerem isoladamente preservadas.

O esquema de Wernicke acaba por ganhar novos componentes (um centro de escrita, um centro visual, e um ponto em que as incontáveis partes do cérebro, para além do córtex cerebral, colocariam em movimento o aparelho de linguagem), mas preserva a ideia essencial: para cada "função psíquica" (2013, p. 19) é possível determinar os elementos materiais correspondentes. As diferentes funções não se conectam entre si e, consequentemente, não se autorregulam, assim como os elementos materiais. Dito de modo mais explícito, caminha-se de um ponto local para outro, sem se conseguir jamais formar uma unidade ou um sistema da linguagem. Ao varrer do aparelho neurológico a possibilidade de um arranjo de sua totalidade, perde-se de vista qualquer referência à auto-organização da matéria na constituição e no funcionamento da linguagem. $\mathrm{O}$ aparelho da linguagem é constituído e movido por uma força mecânica que o percorre de uma parte a outra, sem que se possa compreender, mediante referência às suas partes materiais, $o$ conjunto de suas funções. Da somatória das partes não se chega à compreensão da unidade da linguagem. Sua explicação mecânica nos permite apenas compreender o motivo de algumas de suas funções "estarem totalmente anuladas e as outras permanecerem incólumes", mas não o fato de, na maioria das vezes, uma mesma função da linguagem se encontrar "prejudicada em diferentes graus" (2013, p. 27).

Além de não se compreender a unidade funcional da linguagem, as ideias antes apresentadas estabelecem que o órgão preceda e dite a função por ele realizada. Ou, ainda, que a função de linguagem é antecedida e determinada pelos centros localizáveis no lobo frontal e temporal. Mais ainda, que o órgão se coloca como anterior à função e a impõe. Poderíamos nesse caso pensar em uma espécie de cálculo da função do órgão antes de sua feitura? Certamente, não.

Não queremos com isso afirmar que Freud tenha desistido completamente de uma correspondência entre o aparelho psíquico e o neurológico no texto de 1891. O que queremos conservar do que expusemos antes é o cerne da concepção mecanicista criticada por Freud em Sobre a concepção das afasias. Ou seja, que das partes não se chega à totalidade do funcionamento do aparelho em questão (da linguagem, nesse caso) e que do órgão não chegamos à sua função. A ideia exposta no texto pré-psicanalítico permanece em textos posteriores a 1900. Tomemos dois deles, quais sejam: A interpretação dos sonhos (1900) e Além do princípio do prazer (1920). Nossa intenção é a de argumentar que o psicanalista austríaco não 
opta pela via do mecanicismo seja na construção do aparelho psíquico, seja no que diz respeito às relações entre os seres humanos. Ou seja, ao contrário do que afirma Binswanger, a existência humana não poderia ser reduzida ao simples funcionamento de uma máquina nas combinações matemáticas de elementos quantificáveis. Se o homo natura de Freud se identifica com o homo vita, a vida a que se refere o autor austríaco nada ou muito pouco tem de previsível. E o que nos permite ligar textos escritos em épocas tão distintas é, para usarmos a expressão de Monzani (1989), “um mesmo tipo de operação” presente nesses escritos, que pretendemos retomar a seguir.

Publicada quase uma década após o texto sobre as afasias, $A$ interpretação dos sonhos traz em seu capítulo final a exposição do aparelho psíquico segundo o modelo do arco reflexo. Freud fará referência a duas extremidades desse aparelho - a perceptiva e a motora - e a excitações que correm da primeira para a segunda (na vigília) ou da segunda para a primeira (nas construções oníricas). Das percepções que chegam até o aparelho formam-se, entre as duas extremidades, traços permanentes de modificação - ocasionados pela passagem da excitação - denominados traços mnêmicos. $\mathrm{O}$ conjunto desses traços forma a memória. No livro dos sonhos, Freud afirma que não se trata de encontrar no corpóreo os pontos correspondentes das funções psíquicas, mas no campo representacional. A hipótese localizacionista é claramente afastada por Freud:

\begin{abstract}
Vamos deixar de lado o fato de que o aparelho anímico de que aqui se trata nos é conhecido também como preparado anatômico, e vamos tomar o cuidado de não cair na tentação de determinar a localidade psíquica ( $p$ sychische Lokalität) como algo anatômico. Ficamos sobre o solo psicológico e pensamos somente seguir o convite de representar o instrumento de que se servem os trabalhos anímicos como um microscópio composto, um aparelho fotográfico ou algo semelhante. A localidade psíquica corresponde então a um lugar (Orte) no interior do aparelho, do qual resultam os primeiros níveis da imagem. No microscópio e no telescópio, como se sabe, estas são em parte localizações ideias, zonas em que não há nenhum componente palpável do aparelho (1999 [1900, p. 541]).
\end{abstract}

O autor de $A$ interpretação dos sonhos desautoriza qualquer confusão que possa haver entre os sistemas psíquicos e o sistema neurológico ou qualquer "correspondência, termo a termo, entre os dois sistemas" (ANZIEU, 1989, p. 29. Grifo nosso). O psicanalista austríaco não fará referência a lugares no córtex cerebral ou a qualquer parte da massa encefálica, mas a um lugar virtual no interior do próprio aparelho. Tal como no uso das máquinas antes referidas, não se trata de tomar como objeto de investigação os pontos que compõem as partes físicas da produção da imagem, mas a imagem mesma. É esta que interessa Freud e é a partir desta que a concepção de pulsão e vida psíquica será construída.

Não queremos dizer que o corpo será expulso da psicanálise. Muito pelo contrário: em diversos textos, o psicanalista afirmará que entre o somático e o anímico há uma relação de permeabilidade e que não se pode traçar um limite rígido entre o primeiro e o segundo (para citarmos um exemplo, cf. FREUD, 1999 [1915a]). E o fato de a totalidade do psiquismo ser opaca para a consciência, única instância capaz de construir conhecimento, obriga Freud a tomar um modelo como ponto de apoio para a intelecção do anímico. Esse modelo é tirado do funcionamento do corpo em ação, no máximo de sua simplificação possível, a saber: nas funções elementares de sensação e resposta motora. $\mathrm{O}$ arco reflexo é o modelo para se pensar o funcionamento psíquico mais simples, aos moldes de um como se fosse assim (als ob). Freud não fará referência a células neuronais, mas a excitações que entram no aparelho psíquico pela percepção e buscam se descarregar na extremidade motora. Entre ambas as extremidades (a perceptiva e a motora), surgem marcas permanentes de passagem da excitação, denominadas traços de memória.

É de se olhar com desconfiança as semelhanças entre a hipótese localizacionista apresentada em Sobre a concepção das afasias e o aparelho psíquico construído no capítulo VII de $A$ interpretação dos sonhos. Não estaria Freud seguindo os pressupostos mecanicistas na construção do aparelho psíquico, com a 
diferença de que, ao invés de fazer referência a células, apresenta a releitura virtual do localizacionismo? Não teríamos no texto de 1900 um aparelho que, ao invés de estar recheado com "600 milhões de corpos corticais" capazes de armazenar todo tipo de informações sensoriais, estaria povoado de traços mnêmicos que guardariam, como uma espécie de reservatório, a totalidade de nossas representações? Freud não teria caído nos mesmos problemas que havia criticado nos fisiologistas, já que parece identificar o centro motor de descarga à extremidade motora do aparelho, o centro sensório à extremidade perceptiva, e os muitos milhões de células nervosas aos traços mnêmicos? Ou, em outros termos, os órgãos anímicos não estariam, assim, ditando e determinando a totalidade das funções por eles realizada?

Uma diferença essencial entre a exposição localizacionista e a freudiana deve ser levada em conta: se o modelo utilizado por Freud para apresentar o psiquismo é o do funcionamento corporal, ele não parte de um aparelho psíquico já constituído. Ao contrário, trata-se de expor a constituição ou a fabricação dos órgãos que compõem o psiquismo. Fabricação esta que se inicia a partir de uma função capaz de pôr o psiquismo por inteiro em atividade. Ora, e que função é essa? Segundo o autor, o que dita a construção do aparelho psíquico é a descarga da excitação, que impõe ao psiquismo um sentido na circulação da energia: parte-se do desprazer (aumento do acúmulo de excitação) rumo ao prazer (diminuição do acúmulo) movimento que Freud denomina desejo -, e a realização de desejo será a regra de maior simplicidade e generalidade tanto do funcionamento do aparelho quanto da construção dos sistemas ou órgãos anímicos.

A análise dos sonhos infantis nos fornece o exemplo de que a circulação energética precede a constituição bem acabada desses sistemas ou órgãos. Segundo o psicanalista, os sonhos infantis revelam com franqueza o desejo que realizam; são, por assim dizer, transparentes em sua intenção, uma vez que os diferentes órgãos que compõem o psiquismo ainda não estão inteiramente delimitados. No adulto, entretanto, o sonho é uma realização disfarçada de desejo. Tem, assim, de pressupor que há, nesse último, uma espécie de órgão censor da alma, já bem constituído e delimitado, que não permite a tomada de consciência do desejo, e que se coloca entre o inconsciente e a consciência. As instâncias psíquicas surgem a partir de um movimento energético no interior do próprio aparelho psíquico, que tem como regra fundamental a diminuição do desprazer.

Em Inibição, sintoma e angústia (1999 [1926], p. 121 et seqs), Freud faz clara referência a uma repressão primária que está na origem das primeiras formações inconscientes, mas que não pode ser explicada por um investimento do inconsciente, ainda não diferenciado das outras instâncias. É provável que, segundo o autor, esse processo provenha de um movimento contra um primeiro investimento energético de grande magnitude, isto é, fortemente desprazeroso. Esse contrainvestimento não pode ser outra coisa que uma massa de energia intrínseca ao próprio psiquismo que tem a função de barrar o aumento e o avanço da excitação no interior do sistema. Ele tem início, segundo Freud, no que futuramente será a instância censora. Perguntamo-nos, então, a precedência da descarga energética e da resistência ao aumento de energia intrapsíquica em relação à delimitação das instâncias psíquicas não nos permite pensar uma antecedência da função dos órgãos em relação à confecção destes? Ao que nos parece, sim.

E como entender que as produções anímicas não são a reprodução mecânica de fatos pontuais armazenados na memória? Para responder a essa questão, iremos recorrer a um exemplo de interpretação de sonho. Tomemos o analisado no início do capítulo VII de $A$ interpretação dos sonhos, conhecido como o "sonho do menino que se queima". O autor escreve:

Um pai passou dias e noites ao lado do leito do filho doente. Depois que a criança morreu, ele vai descansar num quarto ao lado, mas deixa a porta aberta para poder ver do seu quarto o cômodo em que se encontra o cadáver amortalhado da criança, rodeado por grandes velas. Um velho foi encarregado de velá-lo e está sentado ao lado do corpo, murmurando orações. Depois de algumas horas de sono, o pai sonha que a criança está ao lado de seu leito, segura-o pelo braço e lhe sussurra em tom de censura: "Pai, não vês que me queimo?". Ele acorda, nota uma luz intensa 
que vem do quarto onde está o corpo, corre até lá, encontra o vigia idoso adormecido e o lençol e um braço do querido cadáver queimados por uma vela que caíra sobre ele (1999 [1900], p. 513).

Expresso de maneira sintética, podemos afirmar que na interpretação desse sonho, Freud retoma algumas das ideias expostas em outros capítulos do texto, a saber: que o sonho é composto por estímulos que chegam no momento presente àquele que dorme, somados a traços mnêmicos do passado recente e remoto. À "luz intensa" que "atinge os olhos do homem adormecido" e à "preocupação de que o vigia idoso não estivesse à altura da tarefa", somam-se traços de memória tais como os das possíveis queixas do filho ("me queimo"), "e as palavras 'Pai, não vês?' [relacionada] com outra ocasião que desconhecemos, mas rica em afetos" (1999 [1900], p. 514). A ligação dos três elementos descritos se deve à realização de desejo, que no caso do sonho antes exposto são, ao menos, dois: o de que a criança estivesse viva e, por causa dessa realização de desejo, o de prolongar o sono por mais alguns momentos: "se o pai tivesse acordado primeiro e então tirado a conclusão que o levou ao quarto do velório, teria, por assim dizer, encurtado a vida da criança em alguns momentos" (1999 [1900], p. 514), bem como o seu próprio repouso.

Pela interpretação, vemos que os estímulos sensíveis que chegam ao pai enquanto ele dorme e os traços mnêmicos (recentes e remotos) são recompostos em uma unidade, tendo em vista a realização de desejo. Mas se a circulação energética é que dita a costura dos elementos oníricos distintos, a percepção sensível e a memória não estariam exercendo em Freud o mesmo papel mecânico que realizavam em Wernicke, isto é, não ofereceriam apenas elementos pontuais mecanicamente agrupados e reproduzíveis pela passagem da energia psíquica? Para o psicanalista austríaco, a memória não é um mero depositário de traços de excitação que, como cópias de sensações, armazenam-se umas após as outras como se houvesse uma duplicação da percepção nas cadeias mnêmicas. O sonho é muito mais do que uma mera reprodução de antigas sensações, reativadas pela passagem de excitação. Segundo Freud, o aparelho psíquico, no seu modo mais elementar de funcionamento, compõe uma cena de tal modo que consiga pôr simultaneamente traços de memória de diferentes épocas da vida em uma mesma cena e lhes dar uma unidade que não tinham anteriormente. Essa composição não é uma mera reprodução do passado, mas a produção de algo original, que, guiada pela realização de desejo, altera o sentido dos acontecimentos efetivos. ${ }^{3}$ Ou melhor, podemos afirmar que, no sonho, o psiquismo toma um material bruto - os traços das vivências efetivas - e modifica o sentido dessas vivências. $\mathrm{O}$ que na efetividade não poderia ser posto em ato se inverte no mundo onírico: todo o sistema psíquico corrobora para figurar uma nova realidade, contrária à efetiva: o filho morto é trazido à vida e o homem prolonga o seu sono para continuar a revivê-lo e vice-versa.

Seria esse processo criativo exclusivo do universo onírico? Tomemos outro exemplo, tirado de Além do princípio de prazer: trata-se de uma "ação enigmática e repetida continuamente" (1999 [1920], p. 11ss) por um menino de um ano e meio, com o qual conviveu algumas semanas e pôde observar por si mesmo. Freud a descreve da seguinte maneira:

Esta boa criança mostrava então o hábito, ocasionalmente incômodo, de atirar para muito longe de si - no canto do quarto, debaixo de uma cama etc. - todos os pequenos objetos que apanhava, de maneira que muitas vezes não era tarefa fácil reunir os seus brinquedos. [...] Um dia fiz a observação que confirmou minha apreciação. A criança tinha um carretel de madeira envolto em um barbante. Jamais lhe ocorria, por exemplo, puxá-lo no chão atrás de si [e] então brincar de carro com ele, mas arremessava com grande habilidade o carretel atado ao fio sobre a beira de sua caminha coberta com véu, de maneira que ele desaparecia ali; com isso dizia seu significativo o-o-o-o [que de acordo com a mãe queria dizer "Fort" (foi embora)] e então puxava novamente o carretel pelo fio, saudava agora seu aparecer com um amistoso " $\mathrm{Da}$ " [ali está]. Esse era, pois, o jogo completo, o de desaparecer e regressar; na maioria das vezes se podia ver apenas o primeiro ato, e esse era repetido por si só incansavelmente como jogo, apesar do maior prazer indubitavelmente aplicar-se ao segundo ato (FREUD, 1999 [1920, p. 12-13]). 
Levou algum tempo para que o sentido da repetição desses dois atos se tornasse claro para Freud. Tratava-se de um primeiro jogo, criado pela própria criança, no qual era posta em cena uma vivência fortemente carregada de afeto. De acordo com Freud, é a ausência da mãe que está por trás do jogo do filho. Essa vivência desagradável é revivida em sua brincadeira, de tal modo que possa aliviar o aumento da excitação (sentido como desprazer), ocasionado pela partida da mãe. A brincadeira infantil aponta para a existência de um jogo de forças que acontece no interior da vida psíquica da criança: nela, substitui-se a vivência efetiva altamente desprazerosa por uma cena capaz de rebaixar os altos investimentos e gerar prazer. Essa substituição é acompanhada da aprendizagem das palavras (Fort-Da) e da tessitura destas com os processos psíquicos de contensão de energia. No jogo infantil, as vivências altamente investidas são contidas e substituídas por uma cena composta tal como quer a criança. Mandar embora e trazer de volta o objeto de madeira possibilita ao pequeno mudar o sentido de sua vivência efetiva e assumir um papel ativo diante de uma experiência originalmente passiva e desagradável. Na brincadeira, "a criança passa da passividade do vivenciar para a atividade do jogar" (1999 [1920], p. 15). Ela não repete meramente o que da efetividade foi gravado em sua memória; ao contrário, ela vai além daquela: se antes ela esperava passivamente a volta da mãe, no jogo, ela a dispensa e a recupera a seu bel-prazer. Freud afirma que tal como nas peças de teatro, o jogo (Spiel) permite à criança abandonar o lugar de espectador diante da vida e assumir o de ator-autor. Ela pode atuar de uma nova maneira e com isso sentir, agir e criar todo um mundo novo segundo o seu arbítrio. Tal como em $A$ interpretação dos sonhos, também aqui vemos a função preceder a forma: o jogo infantil, comandado pela realização do desejo da criança, está na origem da criação de dois mundos distintos - o compartilhado com outros indivíduos (comunicável e possibilitado pelo aprendizado da linguagem) e o mundo privado, da fantasia, ou ainda, da separação entre consciente e inconsciente. Em seu jogo inventado, esses dois mundos aparecem ainda unidos; a criança, em sua brincadeira, não atua tendo em vista um espectador e não se importa com a presença deste. Já o adulto, cuja instância censora se encontra delimitada e desenvolvida, guarda para si, longe dos olhos dos outros e de toda possível comunicação, um mundo apartado daquele compartilhado com os outros homens, ${ }^{4}$ a saber: o mundo de moções de desejos reprimidos.

O jogo infantil revela a grande produção cultural da criança (cf. FREUD, 1999 [1920], p. 12): além da aquisição da linguagem, aprende a renunciar às satisfações imediatas das pulsões. A criança, apesar de estar com pouca idade, já não chorava mais quando abandonada pela mãe, mesmo que sua espera durasse horas. Ela aprendeu a tolerar o acúmulo de excitação, mas não sem uma compensação: no jogo, a criança recria a sua vivência de modo invertido. Nesse mundo à parte, o pequeno assume o lugar do outro (do adulto/mãe), identifica-se com ele e atua como ele. A repetição da experiência desprazerosa é o modo de que a criança dispõe para conter a magnitude do vivenciar, contudo, não como uma simples cópia ou repetição que impeça a edificação de algo próprio. A imitação praticada no jogo é também um exercício de criação e autocriação: a ação sofrida é modificada e corrigida. No jogo, muda-se o sentido da atuação na vida efetiva: aquele que originalmente arremessa é arremessado. A criança, em seu desejo de ser grande e agir como os adultos, assume o papel da mãe e a faz desaparecer sob os véus de sua caminha. Com isso, o pequeno se torna senhor da situação que desprende grande quantidade de desprazer e a repete em um sentido diverso do vivenciado. A ação desagradável à qual a criança é submetida desloca-se sobre a figura da mãe. Os papéis da criança e da mãe invertem-se: o passivo torna-se ativo, e o ativo, passivo. Mas também a figura da mãe é deslocada de sua aparência original: ela ganha uma nova roupagem, reconhecida apenas pela interpretação analítica. No primeiro jogo infantil exposto por Freud, há uma composição de certos elementos, de tal modo que permita a criação de outros, a saber: da linguagem, da separação entre fantasia e efetividade, e da identidade e modo de atuação do indivíduo no mundo.

Podemos, assim, afirmar que há nesse momento tão elementar do funcionamento psíquico, regido pelo escoamento energético, um desenho da subjetividade em um jogo com o outro, que não é apenas um 
objeto para o sujeito, mas também outro sujeito com quem se identifica e corrige a sua posição (passiva) diante dos fenômenos da vida. $O$ exercício de criação no jogo não poderia ser realizado se não estivéssemos diante de um indivíduo que se apodera ativamente de uma excitação extremamente desprazerosa, e que, ao conquistar a linguagem e a renúncia à satisfação imediata das pulsões, abre-se para um mundo de possibilidades ilimitadas de escoamento energético, assim como para um universo compartilhado com o outro que é, tal como aquele que atua, sujeito ativo e autônomo.

E como prever o modo como a efetividade será modificada e corrigida na criação anímica? Se Freud se refere a processos anímicos comuns a todos os seres humanos - escoamento energético, separação de sistemas psíquicos, aquisição da linguagem etc. -, não afirma, contudo, que todos esses fatores se reduzam a um conjunto de acontecimentos passíveis de previsão ou que dissolvam as particularidades de cada um. $\mathrm{O}$ jogo infantil permite entender que os seres humanos são os únicos capazes de se tornar indivíduos e darem um passo além daqueles previamente designados pela espécie.

Para melhor expor essa ideia, gostaríamos de retomar brevemente alguns pontos da teoria pulsional freudiana: devemos levar em consideração que, apesar de ter sua fonte no corpo e de impelir aos mais urgentes escoamentos de energia, ${ }^{5}$ não há uma transposição direta da pulsão para o psiquismo. Em $O$ inconsciente, Freud traçará uma clara distinção entre a agência representante psíquica das moções somáticas e a própria pulsão, não psíquica em si mesma e, consequentemente, inapreensível em si mesma para o psiquismo. Escreve Freud:

Uma pulsão nunca pode se tornar objeto da consciência, mas somente a representação (Vorstellung) que a representa (repräsentiert). Mas também no inconsciente ela não pode ser representada (repräsentiert) de outra forma que pela representação (Vorstellung). Se a pulsão não se atasse a uma representação (Vorstellung) ou não se manifestasse como um estado afetivo (Affektzustand), então nada poderíamos saber dela (1999 [1915b], p. 275-6).

A pulsão, enquanto estímulo endógeno, em seu estado bruto (como excitação mecânica ou química do corpo), não pode como tal jamais alcançar o psiquismo. Quando Freud se refere aos impulsos que põem o aparelho psíquico em ação, não se trata jamais do campo biológico em estado puro, mas de uma tradução deste no psíquico. No aparecimento do representante psíquico da pulsão, é preciso que se pense em uma arte (Kunst) - a da transposição de uma linguagem para outra, ou ainda, de um modo de funcionamento para outro. Sem a versão dos processos de excitação do corpóreo no anímico, não seria possível vencer a barreira da irrepresentabilidade da pulsão. ${ }^{6} \mathrm{E}$ como prever a tradução que cada um dará a esse fundo inapreensível que é a pulsão em si mesma? Não possuindo um objeto biologicamente predeterminado de satisfação, isto é, sobre o qual a excitação pulsional possa ser tramitada, a realização de desejo dos nossos impulsos conta com um infinito número de situações que se apresentam ao longo do desenvolvimento infantil. Durante esse período da vida humana, em que as instâncias psíquicas ainda não estão completamente dissociadas, cada histórico de vida forja ou fixa um modo de escoamento energético. Se Freud faz referência aos caracteres oral, anal, fálico, esses caracteres não estão em contradição com a individualidade. É nos acontecimentos da vida de cada ser humano, nas fases em que se fixou, nos objetos que encontrou para a realização do desejo e nos modos como essa realização se deu que vemos cada indivíduo se afirmar como único. Caso contrário, a posse de um livro de sonhos, que indicasse para cada elemento onírico uma interpretação fixa, bastaria para fazer de qualquer um psicanalista.

Ora, mas não vemos em Além do princípio do prazer Freud fazer referência a uma propriedade universal das pulsões? Tal como ele afirma, elas seriam conservadoras, impeliriam a repetir um estado precedente, como a expressão da natureza conservadora da vida orgânica (1999 [1920], p. 38). Essa definição nos permitiria afirmar uma previsibilidade da vida humana? A previsibilidade ou o cálculo exato do destino humano exigiria uma homogeneidade na relação entre certa causa (biológica, por exemplo) e determi- 
nado efeito, ou, para sermos mais explícitos, uma correspondência ponto a ponto entre o impulso que gera o desejo e a ação que permite o escoamento energético. Podemos afirmar que tal correspondência é incompatível com a individualidade. Para que cada ser humano se caracterize como indivíduo, um número infinito de possibilidades deve haver entre o impulso e a realização do desejo. A criação no sonho e no jogo infantil, tal como vimos anteriormente, são exemplos de como na psicanálise freudiana o cálculo mecânico não pode reger o destino dos homens. Cada indivíduo tem sua história, na qual constrói seus complicados meios de realização de seus impulsos.

E quanto às críticas feitas por Binswanger ao tratamento psicanalítico? Quando Freud faz referência à transformação da repetição em recordação durante o processo analítico, não há aí um processo análogo ao descrito no jogo infantil? A análise é levada a cabo na medida em que o paciente fornece suas informações biográficas; é sua tarefa fornecer esses dados. Nesse movimento de retomada da vida pelo discurso, $\mathrm{o}$ analisando pode tornar-se senhor de si mesmo, e dar um destino que escape à recapitulação passiva tal como vivida na efetividade. Não se pode, desse modo, falar em uma homogeneidade da vida humana ou do tratamento psicanalítico. A esse respeito, escreve Stefan Zweig:

Apenas o conhecimento ativo de si conduz à cura no sentido psicanalítico; é apenas quando o doente é conduzido a si mesmo, à sua personalidade e não a uma banal fé curativa, que ele se torna senhor e mestre de sua doença. A operação, assim, não se faz a partir de fora, mas se cumpre inteiramente nos elementos psíquicos do paciente. $\mathrm{O}$ médico fornece a esse gênero de tratamento apenas sua experiência, sua cuidadosa atenção e sua prudente direção. Ele não tem remédios tal como o médico experiente: sua ciência não é nem formulada nem codificada, ela é destilada pouco a pouco da essência vital do doente (ZWEIG, 2010, p. 93).

Desse ponto de vista, o doente, em seu processo de cura, é um indivíduo ao qual não se pode aplicar mecanicamente leis físicas ou químicas; para cada uma de suas vivências, há uma codificação específica, uma destilação única, de tal modo que se torna impossível reduzir as diferenças qualitativas em quantitativas. Caso isso fosse feito por Freud, a análise seria um processo despersonificado e homogêneo. Ao contrário:

[...] toda cura psicanalítica é um processo formidavelmente complicado, que não tem nada de mecânico e sim de arte: a rigor, ela é talvez comparada à restauração, segundo todas as regras, de um quadro antigo, sujo e repintado por uma mão desajeitada - operação que exige uma paciência prodigiosa, necessária para fazer reviver, milímetro por milímetro, camada após camada, uma matéria preciosa e delicada antes de reaparecer a imagem primitiva sob suas cores naturais (ZWEIG, 2010, p. 100).

A cura é, assim, tal como o jogo infantil, autocriada, assim como envolve uma auto-organização dos diversos elementos psíquicos na realização do desejo. A presença do outro - o analista - é fundamental para isso. Mas o analista, por si só, não pode impor de fora para dentro o processo de cura. Cabe ao paciente criar a sua interpretação, reinventar-se, sair da repetição e recordar. $O$ processo analítico não pode tomar os eventos da vida como meros agregados - novamente, aqui não se vai de um ponto específico a outro. Sobre isso, escreve Zweig: "Mas na cura psicanalítica, o médico verdadeiramente honesto deve, para cada caso individual, encontrar um sistema independente, e esse gênero de adaptação criadora não se ensina, mesmo se colocando nisso inteligência e aplicação" (2010, p. 102).

Ao se levar em conta as ideias expostas sobre a doutrina freudiana, é possível entender que ela não se realiza por um método semelhante ao das ciências naturais, a química e a física, por exemplo, que tratam de seres não individualizáveis, de massas homogêneas. Se Freud reconduz o homem à natureza, tal como descreve Nietzsche em Para além de bem e mal, não elimina do ponto mais elementar dessa natureza a possibilidade de uma autocriação, ou, ainda, de uma "meta-morfose". Desse ponto de vista, não podemos afirmar que há, na obra do psicanalista austríaco, fracas necessidades filosóficas. 
Perguntamo-nos, então: do ponto de vista da obra freudiana, ao se referir ao sonho, ao lado da religião, da moral e das artes como categorias fundamentais da existência, Binswanger não estaria fazendo com a psicanálise o mesmo que, para usarmos os termos de Nietzsche, os "velhos passarinhos metafísicos" fizeram com a filosofia? Para respondermos a essa questão, seria necessário levar em conta outras informações que extrapolam aquelas expostas para a análise da concepção de homo natura.

A leitura de Binswanger influenciou uma geração de leitores e críticos da psicanálise. Freud estava plenamente consciente das objeções às suas ideias, mas não acreditava que elas pudessem colocar seu legado em perigo. Pois, como já afirmamos, se Freud pensava o homem a partir do subsolo, Binswanger o pensava a partir dos andares mais elevados. No final da carta que o psicanalista austríaco dirige ao suíço em resposta à sua conferência proferida por ocasião de seus 80 anos, sintetiza essa querela da seguinte maneira: "Mas parece que falamos sem nos entender, e que nossa disputa somente irá se amainar depois de séculos” (FREUD; BINSWANGER, 1992, p. 237).

\section{REFERÊNCIAS}

ANZIEU, D. (1989) A auto-análise de Freud e a descoberta da psicanálise. Porto Alegre: Editora Artes Médicas Sul.

BINSWANGER, L. (1970) Discours, parcours, et Freud: Analyse existentielle, psychiatrie clinique et psychanalyse. Paris: Gallimard.

. (1954) Le rêve et l'existence. Introdução e notas de Michel Foucault. Paris:

Desclée de Brouwer.

FREUD, S. (2013) Sobre a concepção das afasias: um estudo crítico. Trad. de Emiliano de Brito Rossi. Belo Horizonte: Editora Autêntica.

. (1999 [1898]) Zum psychischen Mechanismus der Vergesslichkeit. In: FREUD, S. Gesammelte Werke. Vol. I. Frankfurt am Main: Fischer Taschenburch Verlag.

. (1999 [1900]) Traumdeutung. In: FREUD, S. Gesammelte Werke. Vol. II/III.

Frankfurt am Main: Fischer Taschenburch Verlag.

. (1999 [1905]) Drei Abhandlungen zur Sexualtheorie. Gesammelte Werke. Vol.

V. Frankfurt am Main: Fischer Taschenburch Verlag.

. (1999 [1914]) Erinnern, Wiederholen und Durcharbeiten. Gesammelte Werke.

Vol. X. Frankfurt am Main: Fischer Taschenburch Verlag.

. (1999 [1915a]) Triebe und Triebschicksale. In: FREUD, S. Gesammelte Werke.

Vol. X. Frankfurt am Main: Fischer Taschenburch Verlag.

. (1999 [1915b]) Das Unbewubte. In: FREUD, S. Gesammelte Werke. Vol. X.

Frankfurt am Main: Fischer Taschenburch Verlag. 
. (1999 [1920]) Jenseits des Lustprinzips. In: FREUD, S. Gesammelte Werke. Vol. XIII. Frankfurt am Main: Fischer Taschenburch Verlag.

. (1999 [1926]) Hemmung, Symptom und Angst. In: FREUD, S. Gesammelte Werke. Vol. XIV. Frankfurt am Main: Fischer Taschenburch Verlag.

MONZANI, L. R. (1989) Freud, o movimento de um pensamento. Campinas: Editora da Unicamp.

NIETZSCHE, F. (1974) Para além de bem e mal: prelúdio de uma filosofia do porvir. In: NIETZSCHE, F. Os pensadores: Obras incompletas. Seleção de textos de Gérard Lebrun, tradução e notas de Rubens Rodrigues Torres Filho. São Paulo: Abril Cultural.

ZWEIG, S. (2010) Sigmund Freud: La guérison par l'esprit. França: Le livre de poche.

\section{NOTAS}

1. Essa citação de Binswanger pode ser encontrada na introdução de Pierre Fédida à tradução francesa do livro Discours, parcours, et Freud (BINSWANGER, 1970, p. 10).

2. Ou ao primeiro giro frontal esquerdo, "se começarmos a contar da fissura de Sylvius". FREUD, 2013, p. 18).

3. Em $A$ interpretação dos sonhos, Freud afirma que o aparelho psíquico, no seu primeiro modo de funcionamento, atuará como um pintor que, ao retratar a Escola de Atenas ou o Monte Parnaso, agrupa em tal pórtico ou montanha filósofos e poetas que jamais estiveram juntos. Temos no sonho uma grande variedade de elementos (distintos no espaço e no tempo), e o psiquismo busca, na maior ou menor afinidade entre eles, compô-los de modo a poder dar uma direção ao escoamento energético. Clara referência à pintura de Rafael, para Freud a memória, mesmo em seu modo de organização mais elementar (pela simultaneidade), não está livre da composição artística ou artificiosa. Segundo esse primeiro modo de organização, representações distantes no espaço e no tempo podem ser colocadas lado a lado, compondo uma unidade e indicando o sentido da realização de desejo (cf. FREUD, 1999 [1900], p. $319)$.

4. Se afirmamos que há a criação de uma cena pintada em nosso psiquismo ou de um papel que se joga ou se põe em ato (spielen) de maneira ativa, não queremos dizer que Freud acredite ou defenda que há, de fato, um autor ou artífice por trás das composições oníricas ou infantis. Ao contrário, a feitura do sonho ou o primeiro jogo infantil são criados cegamente, ou ainda, desprovidos de qualquer inteligência. Contudo, ao fazer referência ao trabalho onírico (de condensação, deslocamento e figurabilidade) ou de atuação infantil e mostrar que o sonho e a brincadeira têm um sentido, que seus elementos são compostos, de tal modo que formem uma comunidade (Gemeinschaft) (1999 [1900], p. 319) representacional, não podemos deixar de nos questionar se, para Freud, eles não poderiam ser dispostos como se fossem intencionalmente organizados. Esse modo mais elementar de organização do psiquismo seguiria o sentido da circulação da excitação (que, como vimos, vai do desprazer ao prazer), capaz de arranjar as representações distantes no espaço e no tempo, de tal modo a dirigir o escoamento de energia pelo caminho mais rápido possível. Derivadas desse modo primário de funcionamento do psiquismo, teríamos construções mais complexas, tais como juízos de verdade e realidade, representações verbais encadeadas e articuladas por preposições que as tornam inteligíveis aos outros etc. Tendo em vista que o funcionamento secundário é derivado do primário, também aquele apontaria para um como se fosse intencional.

5. Em Pulsões e destinos da pulsão, Freud afirma que a pulsão tem sua fonte no corpo, e, ao contrário dos estímulos psíquicos vindos de fora do organismo, não são satisfeitas por ação de fuga. Por isso, pressionam em direção à sua realização com muito mais força que os outros estímulos. 
6. Em Além do princípio do prazer, Freud afirma que, assim como os termos psicológicos, também os fisiológicos, químicos e biológicos "pertencem a uma linguagem figurada [Bildersprache], ainda que nos seja familiar há muito tempo e, talvez, mais simples”. Aquelas ciências corrigiriam com seu vocabulário a psicanálise? Segundo o exposto por Freud, não. Cf. FREUD, 1999 [1920], p. 65. 